2019-4

\title{
Multi-objective Layout Optimization of a Generic Hybrid-cooled Data Centre Blade Server
}

\author{
Assel Sakanova \\ Trinity College Dublin, sakanova@tcd.ie \\ Sajad Alimohammadi \\ Technological University Dublin, sajad.alimohammadi@tudublin.ie \\ Jaakko McEvody \\ Trinity College Dublin
}

See next page for additional authors

Follow this and additional works at: https://arrow.tudublin.ie/engschmecart

Part of the Engineering Commons

\section{Recommended Citation}

Sakanova, A., Alimohammadi, S. McEvody, J., Battaglioi, S. \& Persoons, T. (2019). Multi-objective layout optimization of a generic hybrid-cooled data centre blade server. Applied Thermal Engineering V156, 25 June 2019,pp. 514-523. doi:10.1016/j.applthermaleng.2019.04.071

This Article is brought to you for free and open access by the School of Mechanical and Design Engineering at ARROW@TU Dublin. It has been accepted for inclusion in Articles by an authorized administrator of ARROW@TU Dublin. For more information, please contact arrow.admin@tudublin.ie, aisling.coyne@tudublin.ie, gerard.connolly@tudublin.ie.

Funder: Science Foundation Ireland (SFI); Irish Research Council (IRC)

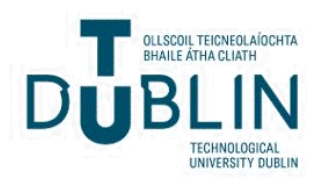




\section{Authors}

Assel Sakanova, Sajad Alimohammadi, Jaakko McEvody, Sara Battaglioli, and Tim Persoons

This article is available at ARROW@TU Dublin: https://arrow.tudublin.ie/engschmecart/62 


\title{
1 Multi-objective Optimization of a Generic Hybrid-Cooled
}

\section{Data Centre Single Blade Server}

\author{
3 Assel Sakanova ${ }^{1, *}$, Sajad Alimohammadi ${ }^{1,2}$, Jaakko McEvoy $^{1}$, Sara Battaglioli $^{1}$ and \\ 4 Tim Persoons ${ }^{1}$ \\ Department of Mechanical \& Manufacturing Engineering, Parsons Building, Trinity College, Dublin 2, Ireland \\ 2 School of Mechanical \& Design Engineering, Technological University Dublin, City Campus, Ireland \\ * Correspondence: email: asse1001@e.ntu.edu.sg; Tel.: +353-830476842
}

Abstract: The rapid global increase in energy demand for data centres requires the continuous improvement of cooling solutions and techniques implemented. In a standard data centre approximately a third of the total power consumption can be attributed to the cooling infrastructure, resulting in raised power usage effectiveness (PUE) values. The main culprits of raised PUE are outdated legacy (air cooled) data centres, where only low grade waste heat is available and its capture and re-use remains a challenge. This study investigates numerically the potential for energy recuperation by a server-level internal layout optimization for a hybrid air/liquid cooled server. The study uses multi-objective genetic algorithms (MOGA) and entropy generation minimization (EGM) techniques to incorporate the multiple objectives involved in solving this problem, and examines the cooling performance and waste heat recovery potential. In order to evaluate the potential of the waste heat recovery the term $\dot{S}_{\Delta T, e x t}$ is introduced in this study. Effect of modified server component layout on pressure drop and maximum outlet temperature were of main interest, due to their role in fan power usage and energy recuperation potential. The base unmodified configuration CFD models were validated through experimental pressure measurements conducted on a real server blade module. The research concluded that a basic server layout optimization such as changing the 
memory module angles and spacing could not only enhance the cooling efficiency but also

26 improve the potential for higher grade waste heat recovery. Overall the decrease in EGM due

27 to server layout optimization could be as high as $15 \%$, while the quality of the waste heat due

28 to temperature uniformity might reach up to $42 \%$.

29 Keywords: Data centre; thermal management; server cooling; multi-objective genetic

30 algorithm optimization; entropy generation minimization; waste heat recovery

\section{$31 \quad$ Nomenclature}

$\begin{array}{ll}A & \text { area }\left(\mathrm{m}^{2}\right) \\ D_{h} & \text { hydraulic diameter }(\mathrm{m}) \\ h & \text { heat transfer coefficient }\left(\mathrm{W} / \mathrm{m}^{2} \mathrm{~K}\right) \\ m & \text { mass flow rate }(\mathrm{kg} / \mathrm{s}) \\ \Delta p & \text { pressure drop }(\mathrm{Pa}) \\ P_{p u m p} & \text { pumping power }(\mathrm{W}) \\ P & \text { perimeter (m) } \\ R_{S e} & \text { Reynolds number } \\ \dot{S}_{b} & \text { entropy generation rate of the baseline server (W/K) } \\ \dot{S}_{\Delta T, \text { int }} & \text { air/liquid heat exchanger }(\mathrm{W} / \mathrm{K}) \\ & \text { entropy generation rate due to heat transfer from DIMM's } \\ & \end{array}$




$\begin{array}{ll}\dot{S}_{\Delta T, i n t}+\dot{S}_{\Delta T, \text { ext }} & \text { entropy generation rate due to heat transfer }(\mathrm{W} / \mathrm{K}) \\ \dot{S}_{\Delta p} & \text { entropy generation rate due to fluid friction }(\mathrm{W} / \mathrm{K}) \\ \dot{S}_{g e n} & \text { total entropy generation rate }(\mathrm{W} / \mathrm{K}) \\ \Delta T & \text { temperature difference }(\mathrm{K}) \\ u & \text { velocity }(\mathrm{m} / \mathrm{s})\end{array}$

\section{$\underline{\text { Subscripts }}$}

$\begin{array}{ll}\text { av } & \text { average } \\ \text { b } & \text { baseline } \\ \text { in } & \text { inlet } \\ \max & \text { maximum value } \\ \text { out } & \text { outlet } \\ \mathrm{R} & \text { ratio } \\ \mathrm{W} & \text { wall }\end{array}$




\section{Introduction}

Data centre electricity consumption has been steadily increasing in recent years due technological advancements in the semiconductor industry and persistent growth in information technology demands. Industry surveys show no slowdown in the power demand for data centre facilities world-wide with an estimated tripling in the next decade [1]. This increasing trend requires improved data centre thermal management solutions to ensure their power consumption is maintained within sustainable limits. The latest summary of the thermal management techniques of data centres from the chip to the cooling system is presented by Khalaj and Halgamuge [2]. Their research investigates state-of-the-art multi-level hybrid thermal management systems, which employ both air and water as the working fluid.

The majority of the studies related to data center thermal management have been concerned with the room or rack level configurations. The existing cooling strategy includes air cooling techniques with limited cooling ability and liquid cooling as highly efficient thermal management technique.

IBM Corporation has played an important role in an industrial research on the advanced electronics cooling. Iyengar and Schmidt [3] developed a model which predicted the energy consumption and the heat transfer characteristics in a data centre. They considered the case study with the load of 5.88MW and concluded the chiller energy is the highest consumer of total cooling energy. In 2008 IBM introduced the water cooling Power 775 Supercomputing system. Ellsworth et al. [4] gave an overview of the water cooling unit and rack manifold. They also highlighted the techniques to improve the cooling performance and enhance the energy efficiency. David et al. [5] presented the experimental characterization of the chillerless air cooled data centre. The paper discussed the thermal, hydraulic characteristics of the airto liquid and liquid-to-liquid rack heat exchanger cooling performance. Schmidt and Cruz [6] 
numerically investigated the effect of the chilled air exiting the hot aisle of a raised floor data centre. The results could be used as a guidance for the data centre layout design. Schmidt [7] described the set of measurement of data centre thermal profile above the raised floor. Schmidt et al. [8] stated that a significant amount of energy could be saved by preventing the mixing of cold and hot air streams. To implement the technique, they introduced separate hot and cold aisles with exhaust chimneys, resulting in energy savings of up to 59\%.

Among academic studies, Kumar and Joshi [9] experimentally investigated the effect of tile air flow rate on the server air distributions located at different places in the rack. They came to the conclusion that increasing the perforted tile air flow rate is not the best way to provide cooling to high density racks. Khalifa and Demetriou [10] developed a simplified analytical model in order to identify the optimum energy-efficient design for air cooled data centres. The methodology also showed the trade-off between the cooling infrastructure and performance characteristics. Karki and Patankar [11] numerically examined the flow field and pressure distribution in the under-floor plenum of the raised-floor data centre within a one-dimensional framework. They also compared the results between a one-dimensional model with that of a three-dimensional model and found a good agreement. Fouladi et al. [12] demonstrated a novel hybrid modelling strategy for data centre cooling system optimization. The employment of proper orthogonal decomposition (POD) airflow modelling scheme demonstrated $23 \%$ and 43\% energy and exergy savings, respectively. Shah et al. [13] proposed the exergy-based approach for data centre thermal management and energy efficiency evaluation. The proposed model quantifies the amount of energy utilized from other components for thermal management purposes. Samadiani et al. [14] developed a simulation-based design approach to achieve an adaptable energy efficient data centre design. This approach helps to investigate the effect of the design parameters in terms of reliability and power consumption minimization.

81 Alkharabsheh et al. [15] summarized the recent advancement in the data centre modelling and 
energy optimization. The paper presented the areas of the potential research for data centre thermal magamanet. Song [16] examined the use of organized fan-assisted tile systems and investigated their impact on the cooling effectiveness. The author came to the conclusion that the technique can significantly improve the cooling performance and might be an interesting research direction in the future.

The internal flow inside a server considering temperature and airflow characteristics has not received much attention, although a detailed analysis addressing the thermal challenges at each level starting from the chip to the entire system could lead to an overall efficiency improvement. Some of the server studies are highlighted as follows. Han and Joshi [17] numerically developed the server CPU and heat sink by using POD which provided faster simulation time with acceptable accuracy. This was used together with the fan controller in order to study the energy consumption reduction in server CPU fans. Sarma and Ambali [18] numerically investigated the thermal design and pressure drop across the $2 \mathrm{U}$ configuration computing server. They concluded that all server components remained under the allowable limit and operated without any failures. Iyengar et al. [19] experimentally studied the concept of hybrid cooling systems, which incorporates air cooling flow low power components (power supplies, storage disk drives, printed circuit board) and water cooling for higher power components (microprocessors and memory cards). Hybrid cooled systems have demonstrated 100 energy savings of up to 30\%. According to Garimella et al. [20] the shift from air to liquid 101 cooling will happen in the near future, which will significantly improve the energy efficiency of next generation data centre facilities.

One underexplored approach to conserving energy is the optimization of the internal layout 104 of the server components, whether by rearranging the components themselves or using baffles 105 to redirect air flow. Here, the former more invasive approach will be taken. Entropy generation 
minimization is one of the techniques to carry out the optimization and evaluate the cooling

107 performance [21]. Server optimization with multiple design variables and global solutions is

108 the aim of this study. Multi-objective genetic algorithm is a proven powerful approach capable

109 of finding trade-off solutions to multiple objective problems.

110 Due to limited supply of fossil fuels and negative consequences of its usage, waste heat

111 recovery as a method to conserve energy is gaining more attention nowadays $[22,23]$. The

112 main challenge in this field consists of capturing and transferring the waste heat in order to

113 increase the recovery system efficiency. Almost $100 \%$ of all electrical power supplied to the

114 data centre server is converted to the heat, which requires a cooling system capable of

115 maintaining the server components below their maximum allowable temperatures. Some

116 research is ongoing to reuse the waste heat in order to reduce data centre operational costs [24].

117 The author proposed the approach which is able to measure the exergy destruction and

118 eliminate irreversibility in the thermal path. Data centre companies such as Facebook and

119 Google with up to $300 \mathrm{MW}$ of power usage are making an effort to reduce energy usage and

120 the waste heat decrease their facilities rate of power waste [25]. Even though most of the data

121 centres operate at $20 \%$ of the maximum load and rarely operates at full load, the total

122 requirement for heat dissipation continues to increase [26]. This indicates that waste heat

123 recovery has the capability to decrease the electricity consumption in data centres.

124 In many studies, for the sake of simplicity in the theoretical calculation, the air temperature

125 and flow distribution at the inlet of the heat exchanger is by default assumed to be uniform

126 [27]. However, in reality the air temperature and flow is generally non-uniform. The non-

127 uniformity significantly degrades both the air-side thermal and hydraulic performance [28].

128 Therefore, temperature and airflow non-uniformity is important and cannot be neglected by the 129 assumption of a uniform distribution. 
In this study, the optimisation of a generic hybrid cooled single blade server is investigated

131 to improve the potential for air-side heat waste recovery, taking into account the outlet air flow

132 non-uniformity. This work extends an earlier study reported on by Sakanova et al. [29] towards

133 a larger parameter space. Also it gives more in-depth insights into the optimization process

134 with a detailed analysis of the effect of the design parameters. At the end the optimized server

135 is compared with the baseline server in terms of the improved ability to recuperate waste heat.

\section{Flow simulation and optimization methodology}

\subsection{CFD model setup and grid independency}

An Intel server board S2600TP with two Intel Xeon E5-2600 v3 processors and 16 DDR3 dual in-line memory modules (DIMMs) is the baseline server under investigation in this study,

140 with a CPU thermal design power (TDP) of 145W [30] and DIMM TDP of 6W per module

141 [19] (Fig. 1). A computational fluid dynamics (CFD) model is developed for both 2D and 3D investigations of the internal server flow. An implicit solver is used to solve governing equations. The second order upwind scheme is applied for energy and momentum discretization. The standard interpolation scheme is adopted for pressure discretization. The pressure-velocity coupling is solved by the SIMPLE algorithm. The convergence criteria are at $10^{-4}$ and $10^{-7}$ for velocity and energy, respectively. The $\kappa-\omega S S T$ turbulence model is applied. According to the $\kappa-\omega S S T$ model requirements, the $y^{+}$value is kept below 1 with the number of prismatic layers of 15 .

The detailed mesh independence study is performed and summarized in Table 1. The grid independence studied based on five consequentially refined mesh generated from the baseline mesh 1 . The next following mesh in refined by refinement factor of 1.32-1.36. The effect of

152 the refining mesh grid is presented in terms of pressure drop across the server. There is a negligible difference (less than 1\%) in pressure drop between mesh 4 and 5 . The discretization 
154 error is also estimated using a method of grid convergence index (GCI) which is performed

155 based on four mesh grids. GCI indicated the maximum uncertainty at each mesh grid stating 156 that the solution are within asymptotic range of convergence [31]. Mesh 4 is chosen as a good 157 trade-off between accuracy and computational time.
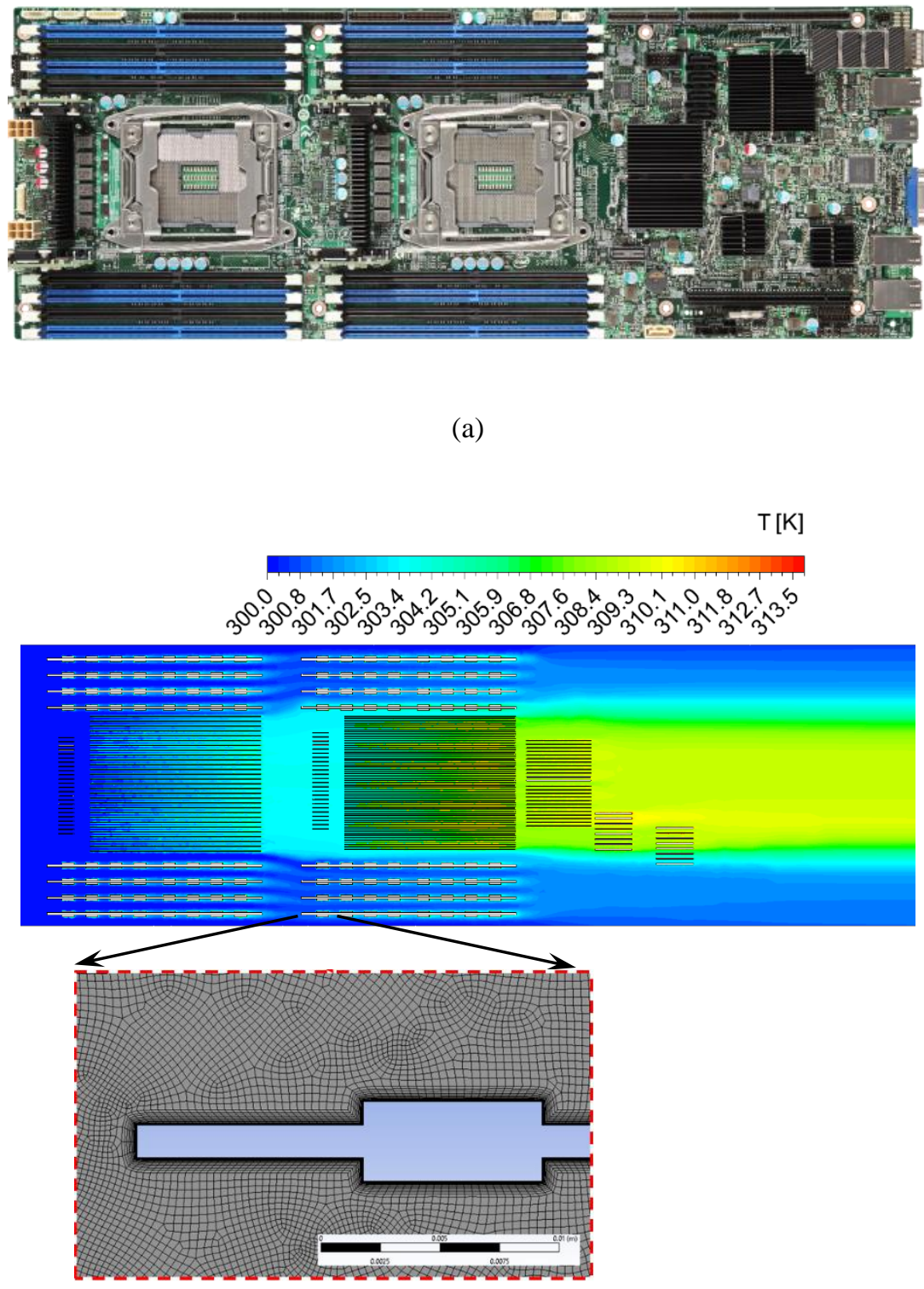

Fig. 1. (a) Intel server board S2600TP and (b) sample CFD simulation temperature 
Table 1. Mesh independence study results

\begin{tabular}{|c|c|c|c|c|c|}
\hline 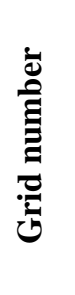 & 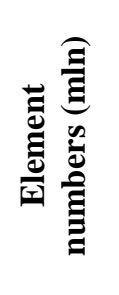 & 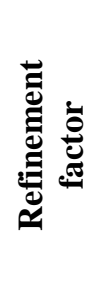 & 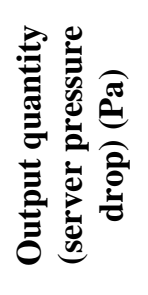 & 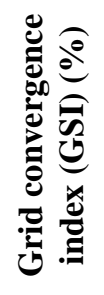 & 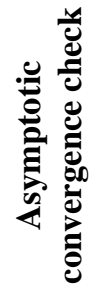 \\
\hline 1 & 1 & N/A & 28 & & \\
\hline 2 & 1.36 & 1.36 & 30.6 & 9.1 & \\
\hline 3 & 1.8 & 1.32 & 31.8 & 4.04 & 1.039 \\
\hline 4 & 2.45 & 1.36 & 36.5 & 1.09 & \\
\hline 5 & 3.29 & 1.34 & 36.8 & 0.07 & 1.008 \\
\hline
\end{tabular}

166

167

168

169

170

171

172

173

174

175

176

177

178

179

180

181

\subsection{Experimental validation}

The experimental validation aims to check the global quantities such as the pressure drop and flow rate and not the local quantities such as velocity fields. The validation is strictly hydraulic in isothermal conditions. The experimental set up consists of a power supply (1), server board, differential pressure transducer (2), flow rate sensors, and a data acquisition system (DAQ) (3) as shown in Fig. 2. The internal three fans [32] boost the room temperature air through the server board at rotational speed of 2,500-20,500 RPM which corresponds to flow rate of 8.8-72.4 cubic feet per meter (CFM). In order to measure the pressure drop across the channel, two pressure taps are installed at the inlet and outlet of the server. The flow sensor is mounted at the server outlet and fixed by means of a 3D-printed mount. The data is logged through National Instruments DAQs controlled through LabVIEW. Additionally, a $70 \mathrm{~cm}$ long smooth duct is attached at the server inlet to establish hydrodynamically fully developed flow at the server inlet. According to [33] the hydrodynamic entrance length in the turbulent flow becomes insignificant beyond a pipe length of 10 times the hydraulic diameter $\left(D_{h}=\right.$ $4 A / P=6.5 \mathrm{~cm})$. At the end, the full system is properly insulated to prevent any additional air to 
182 be sucked in. The obtained experimental results are compared with 2D and 3D simulations as

183 well as with the server fan data sheets [32], as shown in Fig. 3. 2D and 3D simulations and fan

184 server data sheet results show a reasonable agreement with experimental data, with a maximum

185 deviation of $22 \%, 23 \%$ and $18 \%$, respectively.

186 Maximum deviation of 23\% between both 3D and 2D simulation, and experimental results

187 occurs at the lowest flow rate. This increased error can be contributed to a number of different

188 factors. Firstly the differential pressure transmitter/transducer performance is expressed as a

189 percentage of max calibrated span or full scale, which states that the error contribution of the

190 differential pressure transmitter increases as the flow rate/differential pressure drops. For

191 example, according to data sheet, the differential pressure transmitter uncertainty is $+/-0.20 \%$

192 of flow rate at maximum rate; it changes to $+1.27 /-1.28 \%$ of flow rate at the minimum rate. At

193 the lowest flow rate, the pressure discrepancy between simulations and experiments (23\%) was

194 found to be below $2 \mathrm{~Pa}$, well within a reasonable range. Secondly, the simulations cannot 195 capture the complex and rather rough surface of the server board which would contribute to an 196 increased pressure drop.

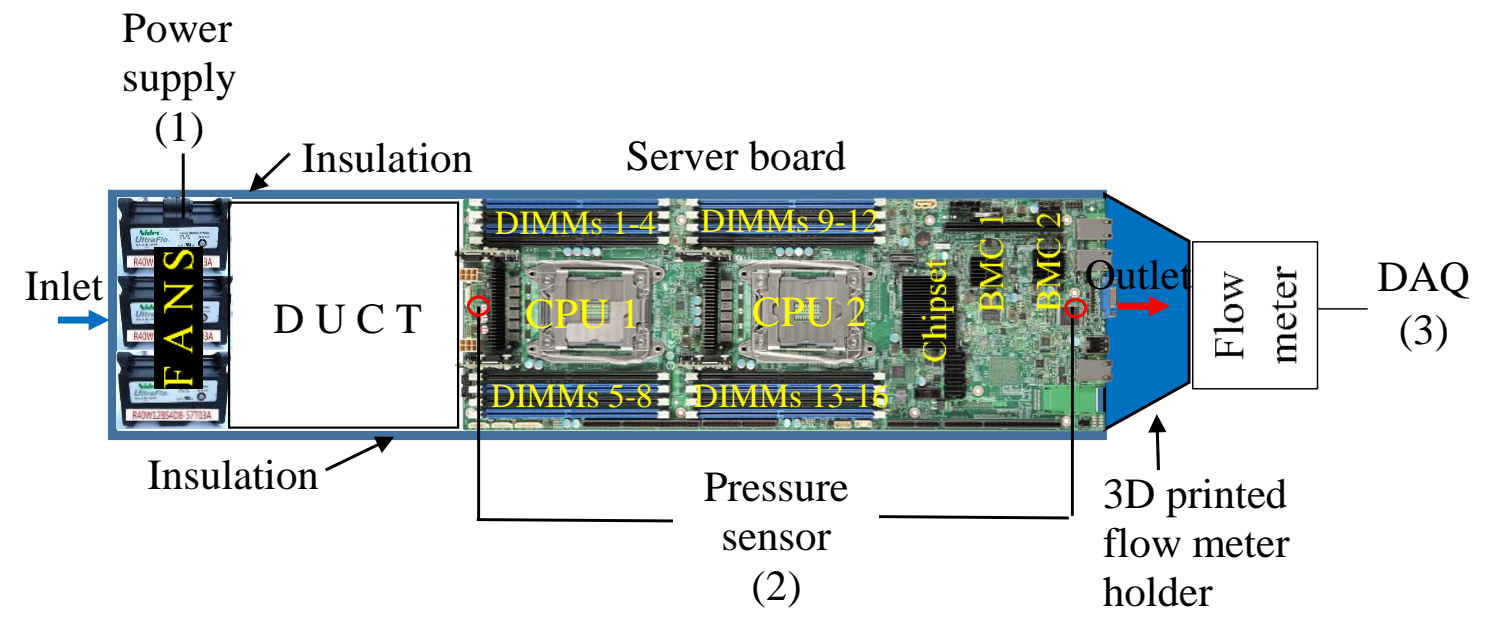




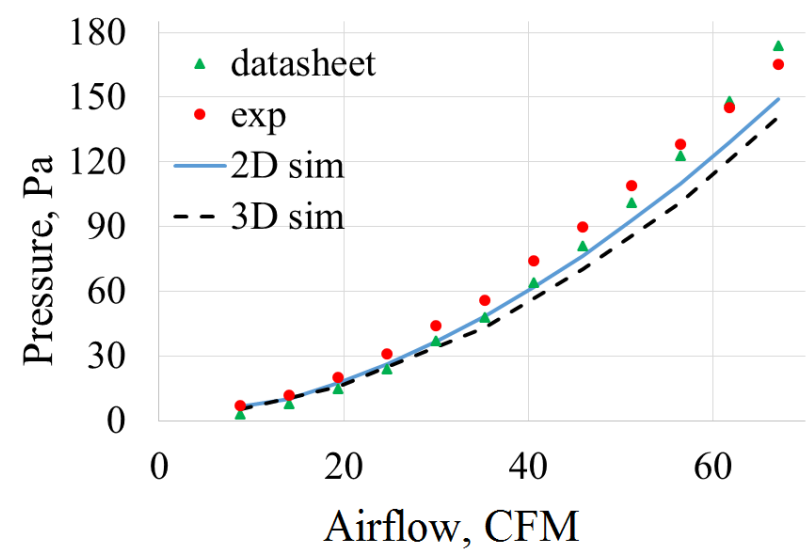

Fig. 3. Experimental validation results (for fans speed ranges 2,500-20,500 RPM)

\subsection{Numerical optimization approach}

In the layout optimization scenario, the CPUs are assumed to be liquid cooled and therefore

204 thermally excluded from the simulation. The aim here is to optimize the air cooling of the

205 remaining components, i.e. the DIMM modules. The CPU heatsinks are removed, and the presence of the liquid-cooled cold plates is assumed to have no significant effect on the air flow due to their significantly reduced profile. upstream DIMM angle $A$, downstream DIMM angle $B$, the cross-stream distance between

210 DIMMs $C$ and the mass flow rate (parameter $D$ ), as shown on Fig. 4. At the inlet to the server,

211 air is blocked from entering the central region (containing the CPUs) by a deflection wall (Fig.

212 4). The open inlet area varies with the angle $A$ since the deflection wall ends at a distance of 7 $213 \mathrm{~mm}$ from the leading edge of the bottom upstream DIMM, as illustrated in Fig. 4. The dashed 214 red lines indicate the DIMM direction when $A>90^{\circ}$. The range of the parameters is 215 summarized in Table 2. 


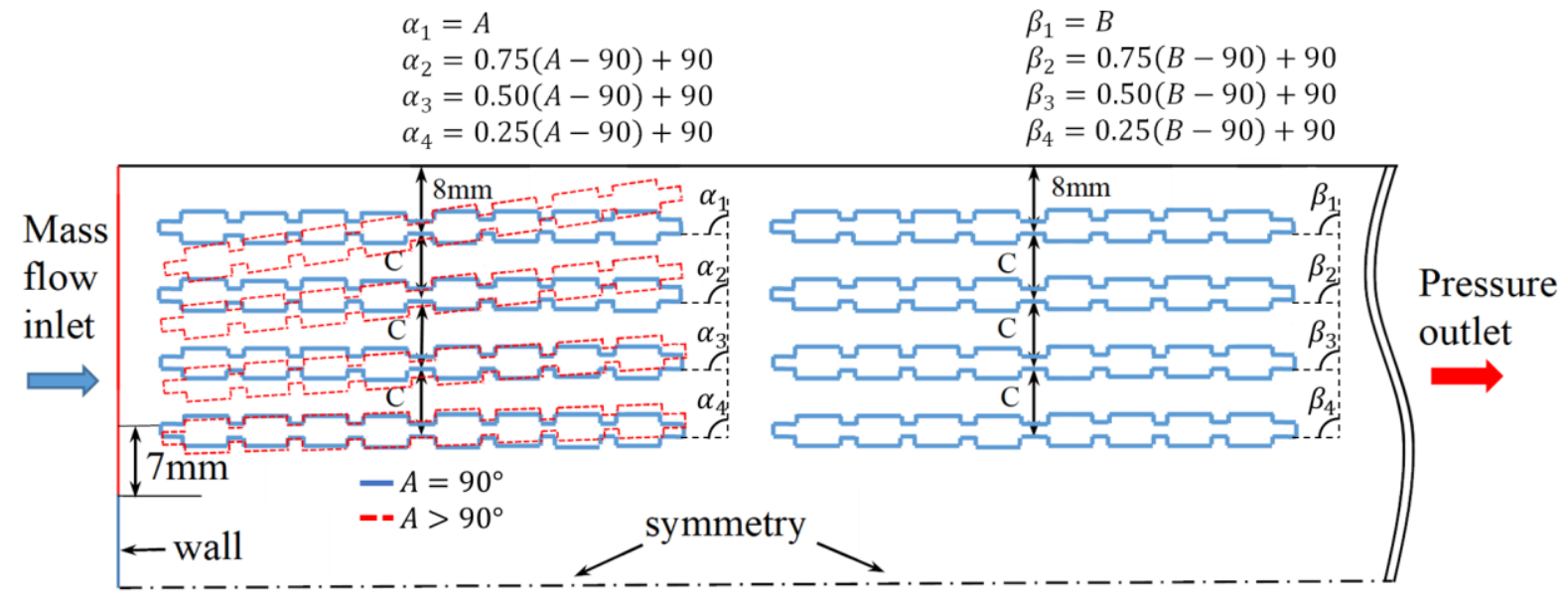

Fig. 4. Numerical optimization parameter definition

Figure 5 depicts the block diagram of MOGA execution. Firstly, the initial population containing $N p o p=50$ is generated. Then the values of the objective functions are obtained for

221 the initial population and evaluated based on the optimization criteria. If the criteria is satisfied then MOGA produces a set of optimal Pareto solitons. However, if the optimization criteria are not met, then based on the reproduction, which includes the crossover and mutation, a new set

224 of candidates is created for evaluation. The procedure is repeated until the optimum solution is 225 found.

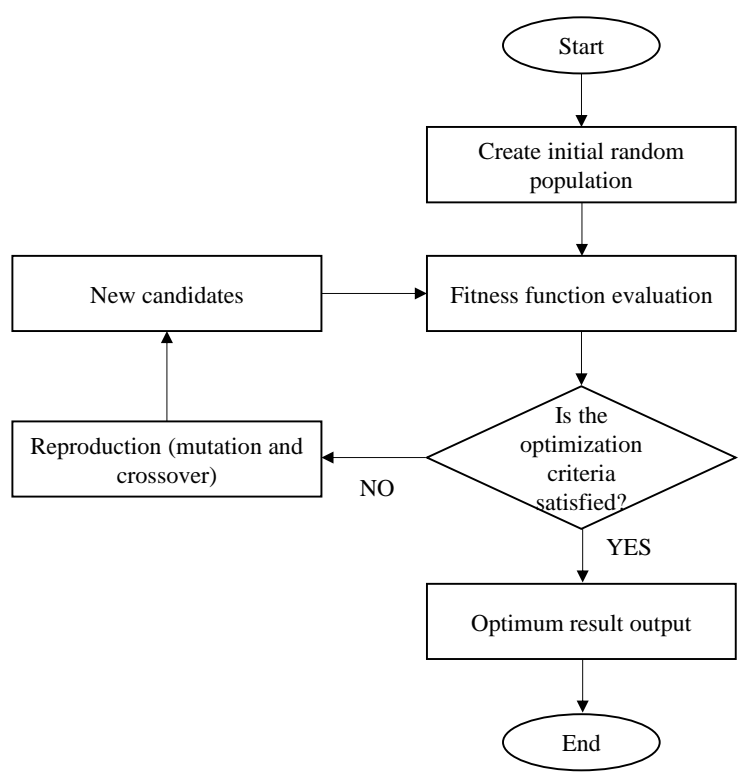


Table 2 includes the design parameters range at which the MOGA optimization analysis 229 is considered. Also the maximum allowable temperature constraint of $90^{\circ} \mathrm{C}$ for DIMM modules 230 is introduced according to [34]. The referenced values of the baseline parameters are taken 231 from the relevant Intel datasheet [30].

Table 2. Overview of the design parameters and thermal constraints

\begin{tabular}{ccc}
\hline Parameter & Range & Reference (baseline server) \\
\hline Upstream/downstream DIMM angle $A$ and $B$ & $85-95^{\circ}$ & $90^{\circ}$ \\
DIMM spacing $C$ & $10-15 \mathrm{~mm}$ & $10 \mathrm{~mm}$ \\
Mass flow rate (parameter $D)$ & $20-24 \mathrm{CFM}(0.15-0.18 \mathrm{~kg} / \mathrm{s})$ & up to $90 \mathrm{CFM}(0.675 \mathrm{~kg} / \mathrm{s})$ \\
Maximum DIMM temperature & $90^{\circ} \mathrm{C}$ & $90^{\circ} \mathrm{C}$ \\
\hline
\end{tabular}
corresponding objective functions, aimed at maximizing the waste heat recovery potential and

236 the coefficient of performance while safeguarding reliability.

Table 3. Overview of the optimization goals, objective functions and constraints

\begin{tabular}{lcc}
\hline \multicolumn{1}{c}{ Goal } & Objective function & Constraint \\
\hline 1. Minimise DIMMs surface temperature & minimize $\dot{S}_{\Delta T, \text { int }}$ & minimize $\dot{S}_{\Delta T, e x t}$ \\
2. Minimize the entropy generation rate in an external air/liquid heat & Keep the maximum DIMM \\
exchanger at the outlet of the server & maximize $\dot{S}_{\Delta p}$ & temperature within the margin $T_{\text {out,av }}$ \\
3. Minimize the pumping power & of $90^{\circ} \mathrm{C}$ \\
4. Maximize the average outlet temperature &
\end{tabular}

EGM is an established method of the optimization, where the objective function is the sum

240 of the entropy generation rate due to heat transfer $\dot{S}_{\Delta T, i n t}+\dot{S}_{\Delta T, \text { ext }}$ and the entropy generation

241 rate due to the fluid friction $\dot{S}_{\Delta p}$, as follows: 


$$
\dot{S}_{\Delta T, i n t} \cong \sum_{k=1}^{N_{\text {DIMM }}} \sum_{j=1}^{N_{\text {chip }}} \frac{q_{j, k}\left(T_{w, j, k}-T_{i n}\right)}{T_{i n}^{2}}
$$

243 where $N_{D I M M}$ is the number of DIMMs $\left(N_{D I M M}=16\right)$ and $N_{\text {chip }}$ is number of chips per

$244 \operatorname{DIMM}\left(N_{\text {chip }}=16\right) . T_{\text {in }}=300 \mathrm{~K} . T_{w}$ is the wall temperature.

245 The entropy generation rate due to fluid friction $\dot{S}_{\Delta p}$ is defined as

$$
\dot{S}_{\Delta p}=\frac{\Delta p u A}{T_{\text {in }}}
$$

246 A rear door heat exchanger is assumed in this work to be mounted on the back of the server

247 to capture the heat of the hot air coming out from the board server and transports it to the chilled

248 water, as shown in Fig.6. This rear door heat exchanger could be a finned coil air/liquid heat

249 exchanger where the fins help to increase the air-side heat transfer area [35].

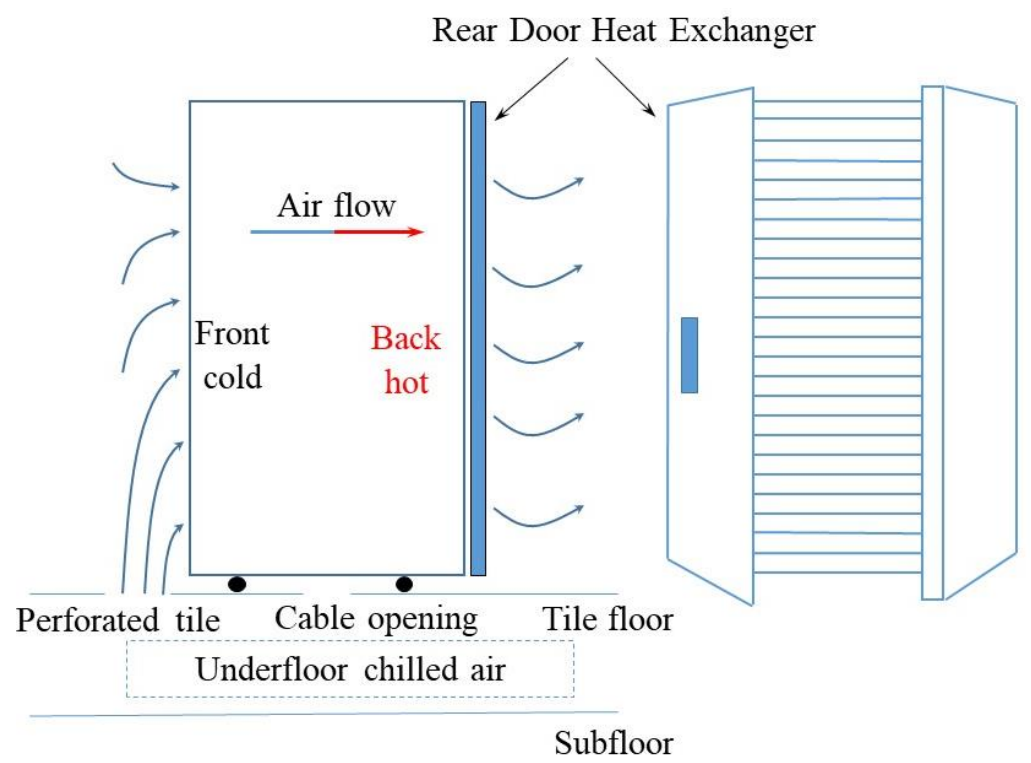

Fig. 6. Rear door heat exchanger 
To evaluate the potential of heat recovery from the air stream, the term $\dot{S}_{\Delta T, \text { ext }}$ is 253 introduced by this study, representing entropy generation rate in an external air/liquid heat 254 exchanger at the outlet of the server:

$$
\dot{S}_{\Delta T, e x t} \cong \sum_{i} \frac{q_{i}\left(T_{o u t, i}-T_{H E X}\right)}{T_{H E X}^{2}}
$$

255

256

The outlet location is divided into a total of $\mathrm{N}=29$ parallel plates, with the distance between plates equal to $0.003 \mathrm{~m}$. At each plate $i=1 \ldots N$, a part of the air stream transfers its heat $q_{i}$ at the temperature $T_{o u t, i}$ to the heat exchanger which is at a constant temperature $T_{H E X}=291 K$ [35]. $T_{\text {out }, i}$ is the local air temperature, evaluated from CFD results at the outlet location $y_{i}$. Where $q_{i}=h A \Delta T$ and $h=N u \cdot k / D_{h}$, where $N u$, Nusselt number, is for laminar flow between two parallel surfaces is defined from [36] with $D_{h}$ as twice the distance between the plates. The total entropy generation rate is the sum of the above mentioned components of entropy generation:

$$
\dot{S}_{g e n}=\dot{S}_{\Delta T, i n t}+\dot{S}_{\Delta p}+\dot{S}_{\Delta T, e x t}
$$

\section{Results}

\subsection{NLPQL and MOGA comparison}

Both non-linear programming by quadratic Lagrangian (NLPQL) and the MOGA method were employed to optimize the server parameters with the single objective of minimizing $\dot{S}_{g e n}$ together with the constraint of keeping the DIMM temperature below $90^{\circ} \mathrm{C}$. NLPQL is a gradient-based method which might not find the global optimum solution without a good starting point. As such, the Screening Direct optimization is performed first and then the results are used as the starting point in NLPQL [10]. The best candidate solutions from both methods are highlighted in Table 4. The solutions from both optimization approaches are in reasonable 
agreement with each other. This verifies the potential of the MOGA method, which will be used in the remainder of this article for a multi-objective optimization.

Table 4. Candidate solution comparison for single objective optimization

\begin{tabular}{llc}
\hline Parameters and outputs & \multicolumn{2}{l}{ Candidate solutions } \\
\cline { 2 - 3 } & NLPQL & MOGA \\
\hline Flow rate $D, \mathrm{~kg} / \mathrm{s}$ & 0.179 & 0.169 \\
Spacing $C, \mathrm{~mm}$ & 10.14 & 10.13 \\
$\dot{S}$ gen, $\mathrm{W} / \mathrm{K}$ & 0.216 & 0.228 \\
Tmax, $\mathrm{K}$ & 362.1 & 361.6 \\
\end{tabular}

\subsection{Local and global sensitivity analysis}

The sensitivity analysis reflects the parameter influence on the optimization targets. The higher the parameter sensitivity coefficient, the greater the impact it has on the output. Hence, the sensitivity analysis helps to determine the dominant parameters. There are two types of sensitivity charts: local and global. The local sensitivity calculates the outputs based on the change of inputs independently. The local parameter sensitivity is based on the difference between the minimum and maximum values obtained by varying one of the input parameter while holding the remaining parameters constant. It means that the local sensitivity depends on the input parameters which are held constant. In this study, the input parameters which are held constant are the manufacturing values of the baseline server. The global sensitivity is based on the correlation analysis of the generated sample point which are located throughout the entire space of input parameters. It means the global sensitivity does not depend on the input (manufacturing) value since all possible values of the inputs have been considered during the analysis. 
Figure 7 shows the local sensitivity trend while Fig. 8 shows the detailed analysis of the

292 local sensitivity stating the actual values of the input/output parameters at the different points.

293 In order to see the impact of input parameters on air flow temperature uniformity at the outlet

294 of the server, the term $\Delta T_{\text {out }}$ is introduced and added to Fig. 7-9. From Fig. 8 DIMM angle $A$

295 has a noticeable positive impact on $\dot{S}_{\Delta p}$ and less significant influence on $\dot{S}_{\Delta T, \text { ext }}$. The positive

296 impact means that $\dot{S}_{\Delta p}$ and $\dot{S}_{\Delta T \text {,ext }}$ increases with $A$. These impacts are opposite to our 297 optimization goals.

298 An increase in DIMM angle $B$ decreases $\dot{S}_{\Delta T, \text { int }}$ more significantly with less penalty in $\dot{S}_{\Delta p}$ as compared with DIMM angle $A$. However as DIMM angle $B$ increases it also contributes to 300 the flow and temperature non-uniformity $\Delta T_{\text {out }}$. In a heat exchanger due to heat transfer, the 301 temperature gradients take place between cold and hot fluids and in the wall separating the 302 fluids. In most of the heat exchanger's heat transfer and pressure drop calculations, the inlet 303 flow and temperature distribution are considered to be uniform, however this assumption could not be accepted as the realistic one. In practice, the air flow and temperature distribution are non-uniform. This non-uniformity has an impact on thermal and hydraulic deteriorations.

306 Temperature uniformity is simply defined as difference between min and max temperatures at 307 the outlet of the server or the inlet to heat exchanger.

The spacing $C$ has a negative impact on $\Delta T_{\text {out }}$ and a positive impact on $T_{o u t, a v}$ which is in

309 line with the optimization targets. This happens while $\dot{S}_{\Delta T, \text { int }}$ dramatically increases with $C$

310 which has an adverse effect on optimization targets.

311 Mass flow rate $D$ has a considerable negative sensitivity coefficient on all objectives apart

312 from $\dot{S}_{\Delta p}$. The higher the flow rate, the smaller $\dot{S}_{\Delta T, \text { int }}, \Delta T_{\text {out }}$ and $\dot{S}_{\Delta T \text {, ext }}$ which corresponds to 
313 our optimization targets. Meanwhile it increases $\dot{S}_{\Delta p}$ and decreases $T_{\text {out }, a v}$ which is against the

314 optimization targets.

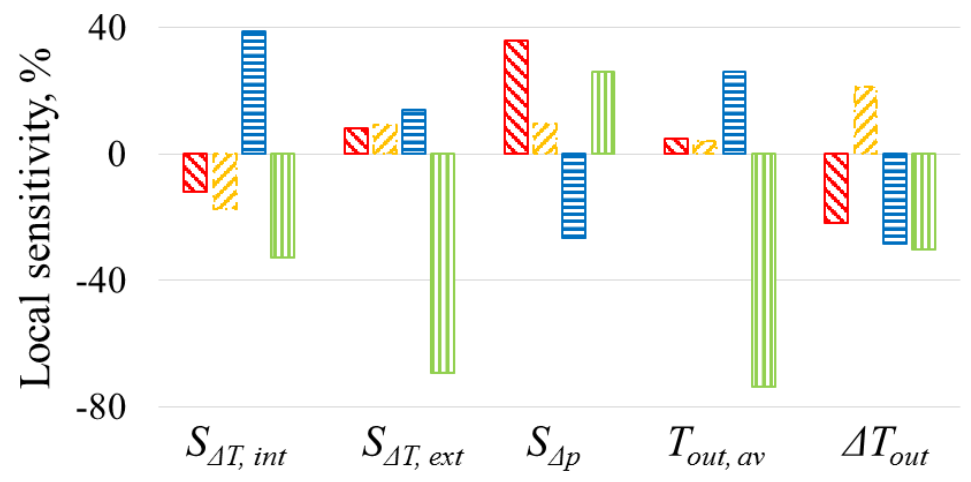

$\triangle$ DIMM angle $\mathrm{A}$ DIMM angle $\mathrm{B} \boxminus$ DIMM spacing $\mathrm{C} \square$ Flow rate $\mathrm{D}$

Fig. 7. Local sensitivity of input parameters on optimization targets and $\Delta T_{\text {out }}$ uniformity

317

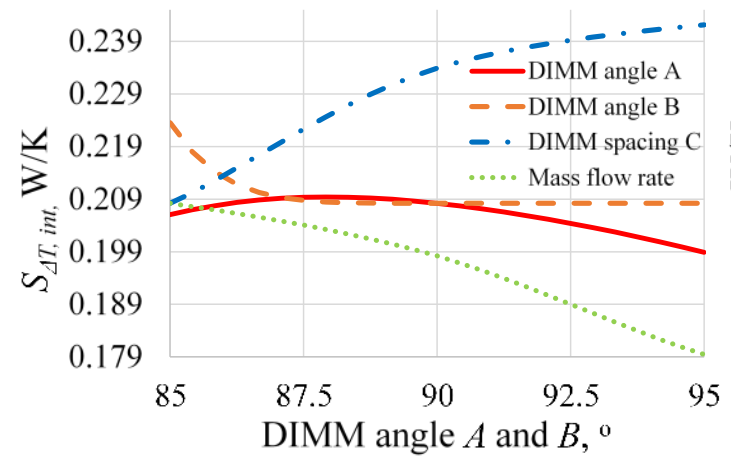

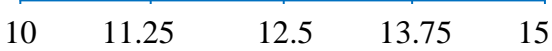
DIMM spacing $\mathrm{C},{ }^{\circ}$

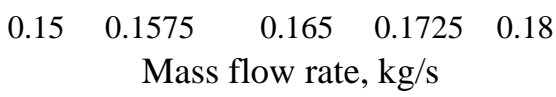

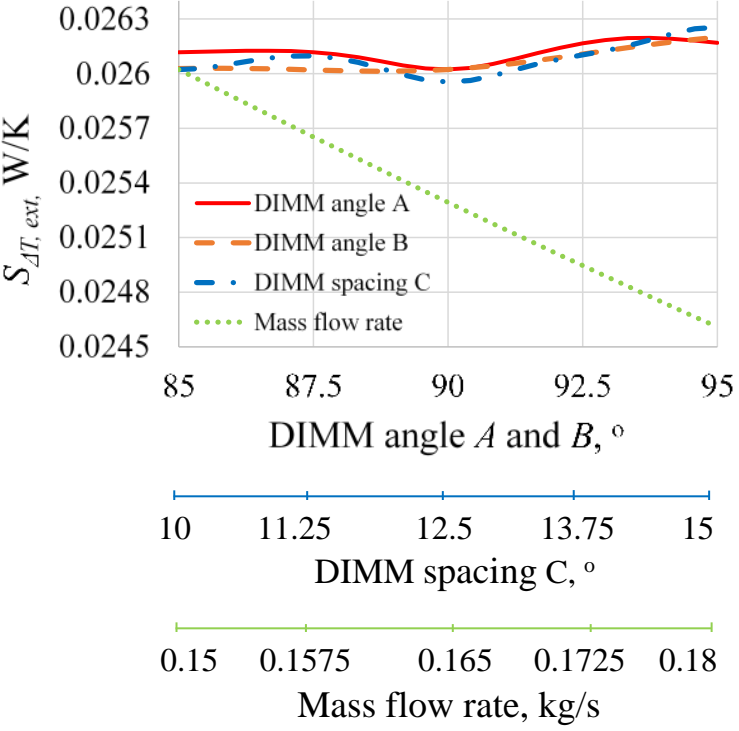

(b) 


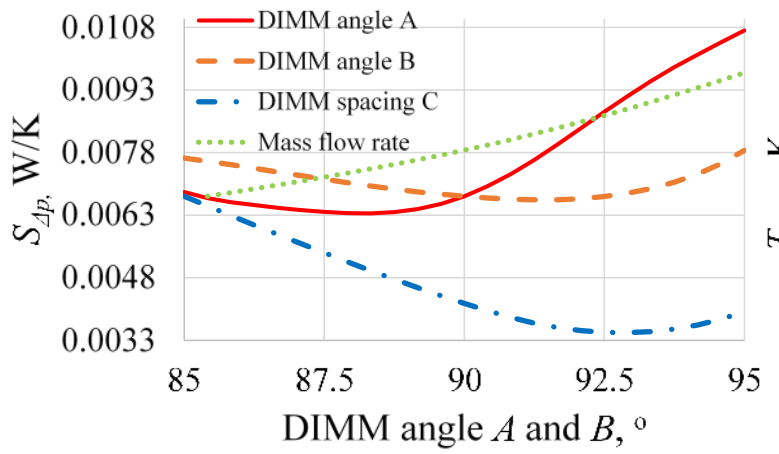

$\begin{array}{cccc}10 \quad 11.25 & 12.5 & 13.75 & 15 \\ \text { DIMM spacing C, }{ }^{\circ} & \end{array}$

$\begin{array}{lllll}0.15 & 0.1575 & 0.165 & 0.1725 & 0.18\end{array}$

Mass flow rate, $\mathrm{kg} / \mathrm{s}$

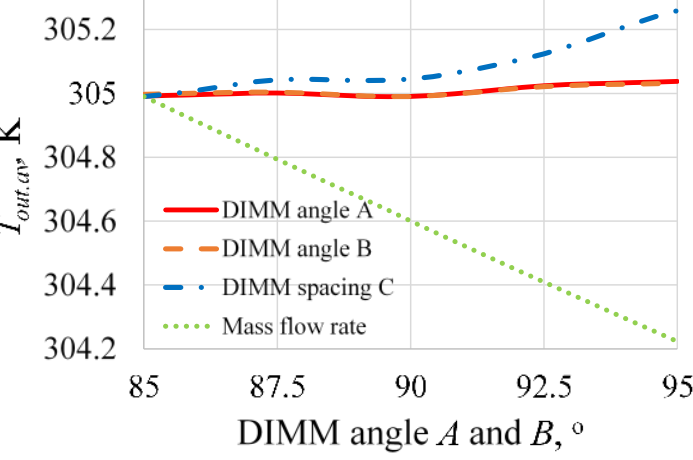

$\begin{array}{lllll}10 & 11.25 & 12.5 & 13.75 & 15\end{array}$ DIMM spacing $\mathrm{C},{ }^{\circ}$

$\begin{array}{lllll}0.15 & 0.1575 & 0.165 & 0.1725 & 0.18\end{array}$ Mass flow rate, $\mathrm{kg} / \mathrm{s}$

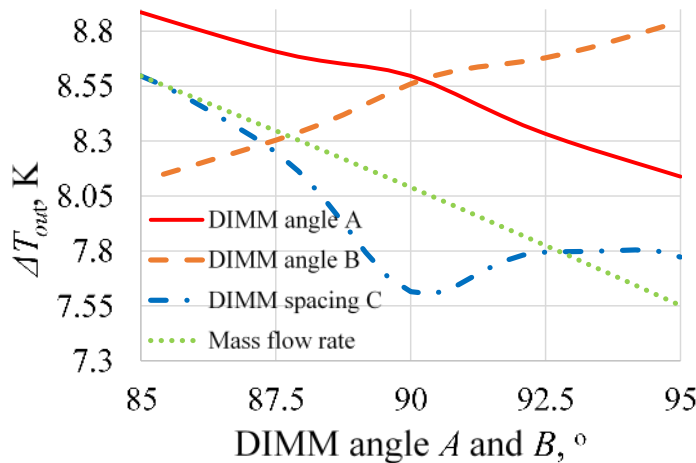

\begin{tabular}{|c|c|c|c|c|}
\hline 10 & 11.25 & 12.5 & 13.75 & \\
\hline
\end{tabular}

$\begin{array}{lllll}0.15 & 0.1575 & 0.165 & 0.1725 & 0.18\end{array}$

Mass flow rate, $\mathrm{kg} / \mathrm{s}$ 

main trends are kept the same. The highest effect among all input variables on the optimization targets has mass flow rate $D$ followed by DIMM spacing $C$ and DIMM angle $A$. The least influenced parameter is DIMM angle $B$. An increase in flow rate $D$ is in line with all optimization goals by neglecting the $T_{\text {out,av }}$ due to small range of change. However the

334 increase in $\dot{S}_{\Delta p}$ is a penalty for the improved optimization goals. An increase in DIMM spacing $C$ can decrease this penalty but at the price of degrading other outputs.

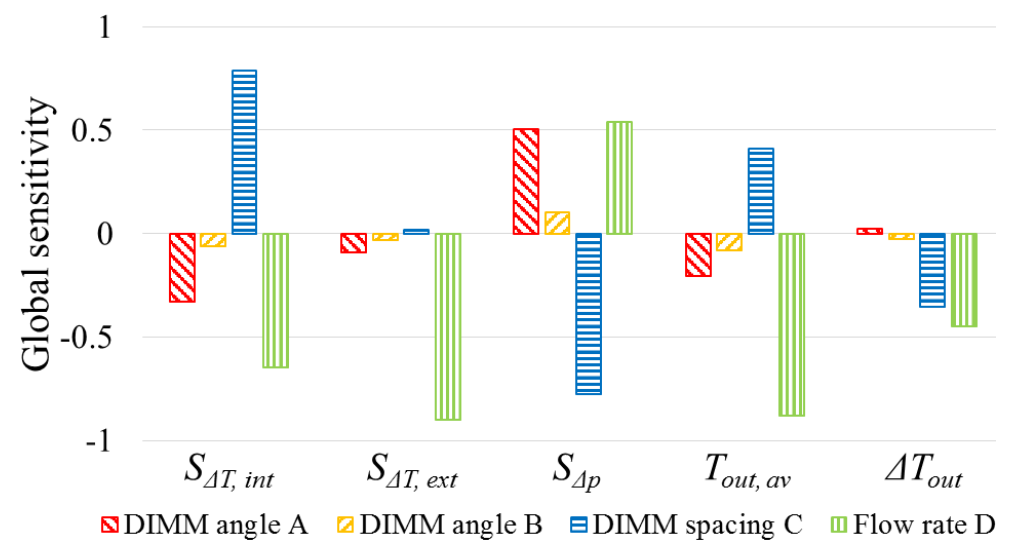

Fig. 9. Global sensitivity of input parameters on optimization targets

\subsection{Optimization effect on EGM and $T_{\text {out }, \text { av }}$}

Fig. 10 illustrates the obtained Pareto-optimal front for the optimization goals. The Pareto-

340 optimal front is a set of non-dominated solutions where all solutions are considered equally

341 good and none of the objective functions can be improved without worsening the other one.

342 However, by including a subjective preference, i.e., using a single goal on any of the optimization goals, the green dots would be considered the best compromise based on EGM

344 and $T_{\text {out }, \text { av }}$ maximization targets. 

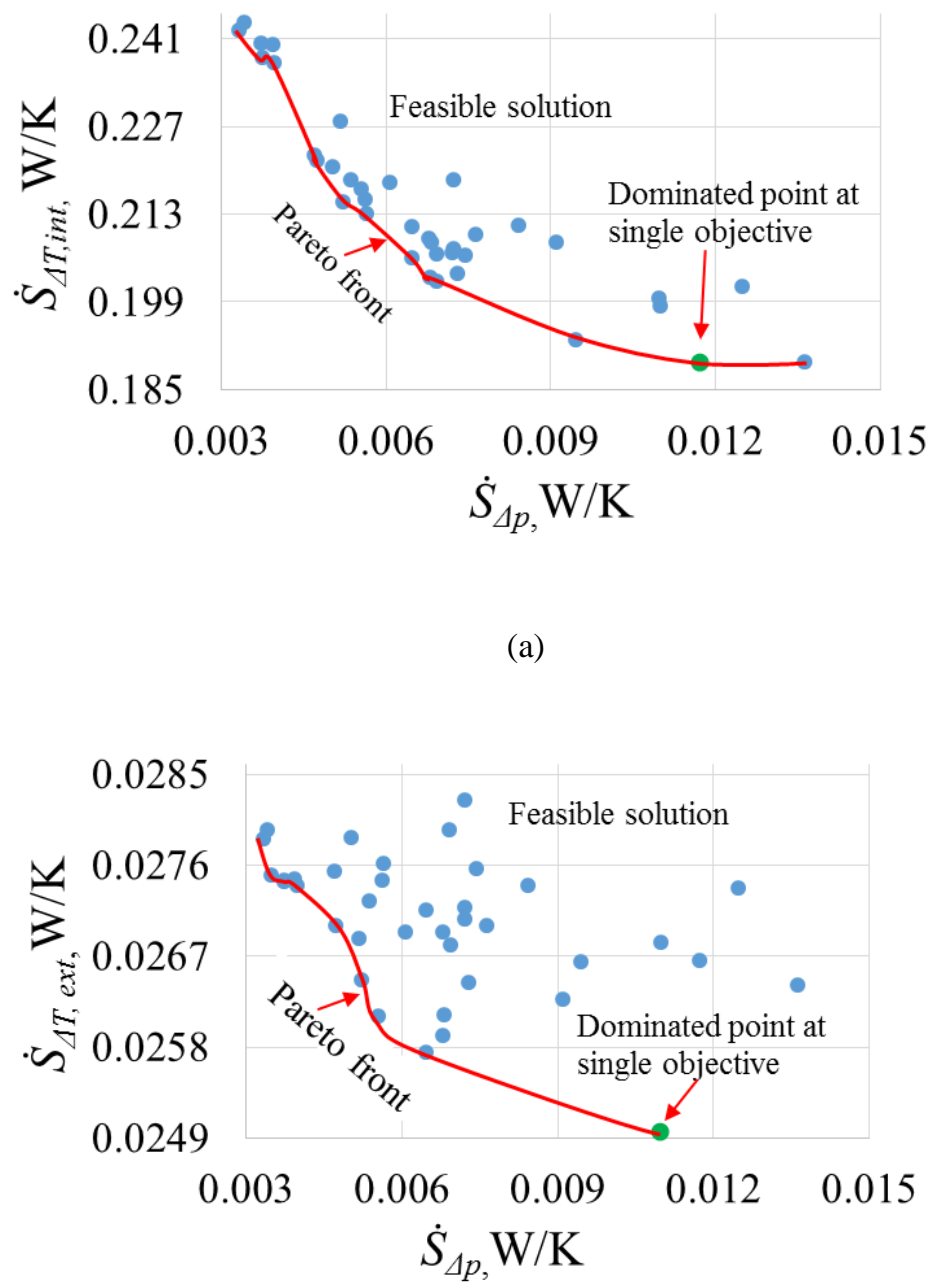

348

(b)

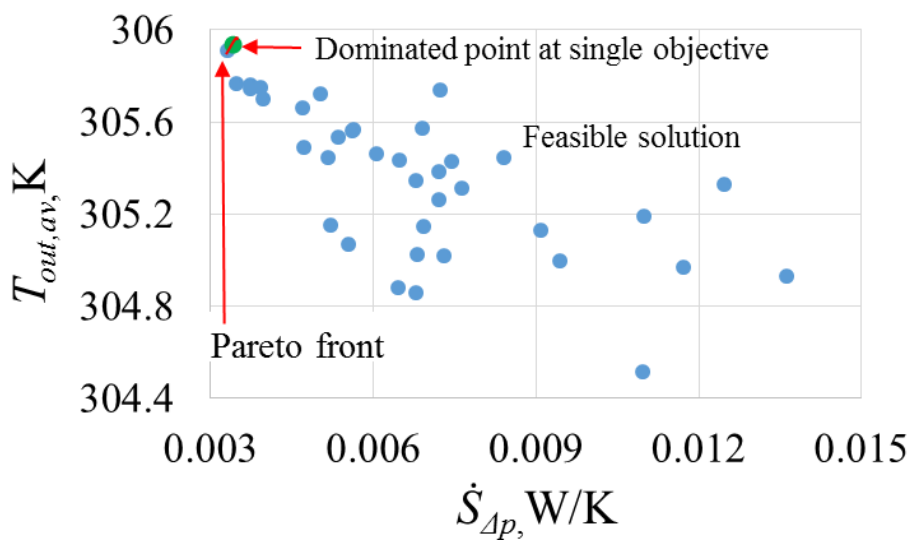


Fig. 11 shows the average outlet temperature $T_{\text {out }, a v}$ (dashed line) and $\Delta T_{\text {out }}$ uniformity

354 (solid line) of the baseline and optimized server layout selected based on the highest possible

$355 \Delta T_{\text {out }}$ uniformity. Only a slight increase in $T_{o u t, a v}$ is observed in the optimized server layout,

356 while the $\Delta T_{\text {out }}$ uniformity is more affected. In order to measure the thermodynamic effect of

357 the improved geometry of the server with respect to the baseline, the entropy generation ratio

358 and temperature uniformity ratio are introduced and defined as $\dot{S}_{R}=1-\dot{S}_{\text {tot }} / \dot{S}_{b}, \Delta T_{\text {out }, R}=$

$3591-\Delta T_{\text {out }} / \Delta T_{\text {out }, b}$. Table 5 summarizes a few examples of some improved geometry

360 compared to the baseline. According to it, $\dot{S}_{R}$ may decrease by up to15\% and the temperature

361 uniformity, $\Delta T_{\text {out }, R}$ which defines the waste heat quality by up to $42 \%$.

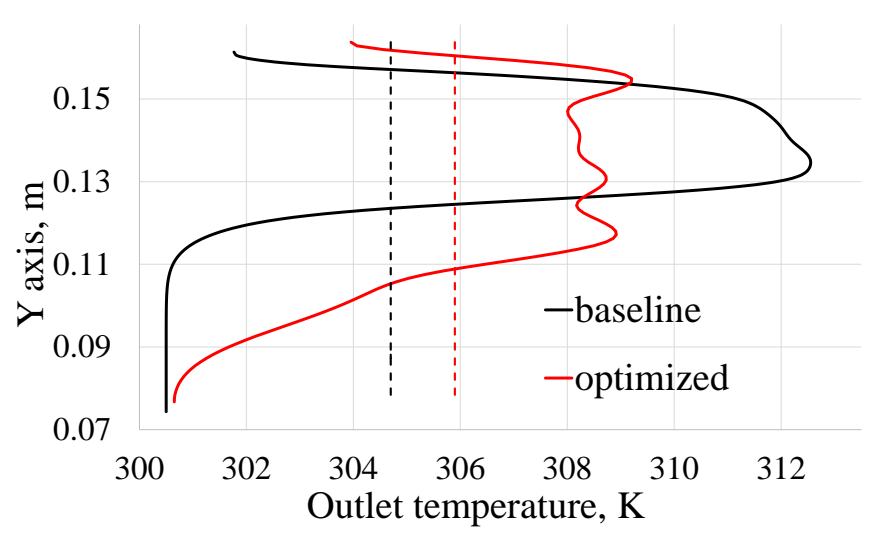

363 Fig. 11. Outlet temperature profiles showing $T_{\text {out }, \text { av }}$ and $\Delta T_{\text {out }}$ uniformity for the baseline

Table 5. Comparison of the optimized server with the baseline one

\begin{tabular}{|c|c|c|c|c|c|c|c|c|c|}
\hline \multirow[t]{2}{*}{ Geometry } & \multirow[t]{2}{*}{ Input parameters } & $\dot{S}_{\Delta T, \text { int }}$ & $\dot{\boldsymbol{S}}_{\Delta p}, W / K$ & $\dot{S}_{\Delta T, \text { ext }}$ & $\dot{S}_{g e n}$ & $\Delta \boldsymbol{T}_{\text {out }}, K$ & $T_{\text {out }, a v}$ & \multirow[t]{2}{*}{$\dot{S}_{R}, \%$} & \multirow{2}{*}{$\begin{array}{l}\Delta \boldsymbol{T}_{\text {out }, \boldsymbol{R}}, \\
\%\end{array}$} \\
\hline & & $W / K$ & & $W / K$ & $W / K$ & & $K$ & & \\
\hline Baseline & $A=90^{\circ} \mathrm{C}$ & 0.22907 & 0.0058 & 0.0268 & 0.2677 & 12.0 & 304.25 & - & - \\
\hline
\end{tabular}




\begin{tabular}{|c|c|c|c|c|c|c|c|c|c|}
\hline & $C=10 \mathrm{~mm}$ & & & & & & & & \\
\hline & $D=0.2237 \mathrm{~kg} / \mathrm{s}$ & & & & & & & & \\
\hline \multirow[t]{4}{*}{ Geometry 1} & $A=92.78^{\circ} \mathrm{C}$ & 0.18926 & 0.01172 & 0.0266 & 0.22765 & 9.3 & 304.97 & 15 & 22.5 \\
\hline & $B=87.075^{\circ} \mathrm{C}$ & & & & & & & & \\
\hline & $C=10.284 \mathrm{~mm}$ & & & & & & & & \\
\hline & $D=0.1791 \mathrm{~kg} / \mathrm{s}$ & & & & & & & & \\
\hline \multirow[t]{4}{*}{ Geometry 2} & $A=94.78^{\circ} \mathrm{C}$ & 0.1996 & 0.0109 & 0.0249 & 0.2355 & 7.1 & 304.52 & 12 & 42 \\
\hline & $B=90.41^{\circ} \mathrm{C}$ & & & & & & & & \\
\hline & $C=12.784$ & & & & & & & & \\
\hline & $D=0.1797 \mathrm{~kg} / \mathrm{s}$ & & & & & & & & \\
\hline \multirow[t]{4}{*}{ Geometry 3} & $A=94.38^{\circ} \mathrm{C}$ & 0.18945 & 0.0136 & 0.0264 & 0.2295 & 8.4 & 304.93 & 14 & 30 \\
\hline & $B=94.483^{\circ} \mathrm{C}$ & & & & & & & & \\
\hline & $C=11.066 \mathrm{~mm}$ & & & & & & & & \\
\hline & $D=0.1767 \mathrm{~kg} / \mathrm{s}$ & & & & & & & & \\
\hline
\end{tabular}

\section{Conclusions}

368 In the present study, an internal layout optimization for a hybrid air/liquid cooled data

369 centre server is performed using the MOGA approach. Entropy generation minimization and

370 an average outlet temperature $\boldsymbol{T}_{\text {out,av }}$ maximization are specified as the optimization goal. The

371 effect of DIMM angles $A$ and $B$, cross-stream distance between DIMMs $C$ and mass flow rate

$372 D$ are also investigated. In order to evaluate the potential of the waste heat recovery the term

$373 \dot{\boldsymbol{S}}_{\boldsymbol{\Delta} \text {,ext }}$ was introduced in this study. The effect of air flow and temperature non-uniformity,

$374 \Delta \boldsymbol{T}_{\text {out }}$ is considered and monitored. The following conclusions are made during the analysis: 
- The flow rate is found to be the most dominated input parameter, followed by DIMM spacing $C$ and DIMM angle $A$ accordingly. The least influenced parameter is DIMM angle $B$;

- An increase in flow rate is in line with the optimization goals but it costs an essential increase in $\dot{\boldsymbol{S}}_{\boldsymbol{\Delta} \boldsymbol{p}}$. An increase in DIMM angle $A$ is also noticeably contribute to the $\dot{\boldsymbol{S}}_{\Delta \boldsymbol{p}}$

- An increase in DIMM spacing $C$ can curb the growth of $\dot{\boldsymbol{S}}_{\boldsymbol{\Delta} \boldsymbol{p}}$ with increasing angle A, but it markedly contributes to $\dot{S}_{\Delta T, i n t}$ which is counter to the optimization goals;

- All input parameters do not significantly change the range of $\boldsymbol{T}_{\text {out }, \boldsymbol{a v} \text {. The }}$ difference in $\boldsymbol{T}_{\boldsymbol{o u t}, \boldsymbol{a v}}$ is within few degrees between the baseline and optimized server;

- The visible contribution on $\Delta \boldsymbol{T}_{\text {out }}$ uniformity during the optimization are made by an increase in all parameters except DIMM angle $B$;

- Overall the decrease in EGM due to server layout optimization $\left(\dot{\boldsymbol{S}}_{\boldsymbol{R}}\right)$ could be as high as $15 \%$, while the quality of the waste heat due to temperature uniformity $\Delta \boldsymbol{T}_{\text {out }, \boldsymbol{R}}$ might reach up to $42 \%$.

The MOGA approach shows a great potential, making it a suitable tool for hybrid-cooled promising way of improving the data centre cooling system reliability and also increasing the

394 potentiality for waste heat recovery. The future research direction is considered as the 395 investigation of the cooling optimization measures at the rack level. 
This publication has emanated from research conducted with the financial support of

399 Science Foundation Ireland under the SFI Strategic Partnership Programme Grant Number

400 SFI/15/SPP/E3125. The authors also acknowledge the financial support of the Irish Research

401 Council (IRC) under grant number GOIPD/2016/216, and acknowledge the

402 DJEI/DES/SFI/HEA Irish Centre for High-End Computing (ICHEC) for the provision of 403 computational facilities and support.

404

405 References

406 [1] Global warming: Data centres to consume three times as much energy in next decade, experts warn. https://www.independent.co.uk/environment/global-warming-data-centres-to-consume-three-times-as-muchenergy-in-next-decade-experts-warn-a6830086.html, 2016 (accessed 1 December 2018)

409 [2] A. Habibi Khalaj and S. K. Halgamuge, A Review on efficient thermal management of air- and liquid-cooled data centers: From chip to the cooling system, Appl Energy $205 \quad$ (2017) 1165-1188. https://doi.org/10.1016/j.apenergy.2017.08.037.

412 [3] M. Iyengar and R. Schmidt, Analytical Modeling for Thermodynamic Characterization of Data Center Cooling Systems, J. Electron. Packag. 131 (2) (2009) 021009-021009-9. https://doi.org/10.1115/1.3103952.

414 [4] J. M. J. Ellsworth, G. F. Goth, R. J. Zoodsma, A. Arvelo, L. A. Campbell, and W. J. Anderl, An Overview of the IBM Power 775 Supercomputer Water Cooling System, J. Electron. Packag. 134 (2) (2012) 020906-020906-9. 
417 [5] M. David et al., Experimental characterization of an energy efficient chiller-less data center test facility with warm water cooled servers, in 2012 28th Annual IEEE Semiconductor Thermal Measurement and Management

[6] R. Schmidt and E. Cruz, Raised floor computer data center: effect on rack inlet temperatures of chilled air exiting

[7] R. Schmidt, Thermal profile of a high-density data center: Methodology to thermally characterize a data center,

[8] R. Schmidt, Energy savings through hot and cold aisle containment configurations for air cooled servers in data centers, Proceedings of the ASME 2011 Pacific Rim Technical Conference and Exposition of Packaging and Integration of Electronic and Photonic Systems (2011) 1-6. https://doi.org/10.1115/IPACK2011-52206. distribution in a high density data center, in 2010 12th IEEE Intersociety Conference on Thermal and Thermomechanical Phenomena in Electronic Systems, 2010, pp. 1-7. Environ. 41 (6) (2006) 734-744. https://doi.org/10.1016/j.buildenv.2005.03.005. 
[13] A. J. Shah, V. P. Carey, C. E. Bash, and C. D. Patel, Exergy Analysis of Data Center Thermal Management Systems, cooling system, Appl. Therm. Eng. 118 (2017) 714-723. https://doi.org/10.1016/j.applthermaleng.2017.02.122. Semiconductor Thermal Measurement and Management Symposium (SEMI-THERM), 2012, pp. 20-27. Intersociety Conference on Thermal and Thermomechanical Phenomena in Electronic Systems (ITherm), 2017, pp. 840-849. 2012 28th Annual IEEE Semiconductor Thermal Measurement and Management Symposium (SEMI-THERM), 2012, pp. 212-223. (2017) 1191-1205. https://doi.org/10.1109/TCPMT.2016.2603600. 
[22] K. Zhang, Y. Zhang, J. Liu, and X. Niu, Recent advancements on thermal management and evaluation for data centers, Appl. Therm. Eng. 142 (2018) 215-231. https://doi.org/10.1016/j.applthermaleng.2018.07.004.

461

[23] Z. He, T. Ding, Y. Liu, and Z. Li, Analysis of a district heating system using waste heat in a distributed cooling data compute density data centers to assure system inlet air specifications. , In; Proceesings of IPACK'01

K. Shen, Z. Zhang, Z. Zhang, and Y. Yang, Investigation of effect on cross-flow heat exchanger with air flow nonuniformity under low Reynolds number, Adv. Mech. Eng. 9 (7) (2017) https://doi.org/10.1177/1687814017708088. heat exchanger dynamic performance, Int. J. Heat Mass Transfer 79 (2014) 1048-1058. https://doi.org/10.1016/j.ijheatmasstransfer.2014.09.011. Optimization for Air-Side Heat Recovery, in 2018 24rd International Workshop on Thermal Investigations of ICs and Systems (THERMINIC), 2018. https://doi.org/10.1109/THERMINIC.2018.8593309. 
480 [31] S. Alimohammadi, D. B. Murray, and T. Persoons, Experimental validation of a computational fluid dynamics methodology for transitional flow heat transfer characteristics of a steady impinging jet, J. Heat Transfer 136 (9) (2014) https://doi.org/10.1115/1.4027840.

[32] Nidec fan R40W12BS4D8-07. https://datasheet.octopart.com/R40W12BS4D8-07-Nidec-datasheet-16750012.pdf,

[33] Yungas A.Çengel and J. M. Cimbala, Fluid mechanics : fundamentals and applications (1st ed.). (McGraw-Hill series in mechanical engineering). Boston: McGraw-Hill Higher Education 2006.

[34] 4Gb: x8, x16 Automotive DDR3L SDRAM. https://www.micron.com/resource-details/cf973726-4e7c-449f-826b-

[35] IBM Rear Door Heat eXchanger. ftp://ftp.software.ibm.com/software/uk/itsolutions/optimiseit/energy-efficiencysolutions/3-product-ibm-rear-door-heat-exchanger.pdf, 2005 (accessed 13 March 2018) 